\title{
'The Cringe Report': why patients don't dare ask questions, and what we can do about that
}

\author{
Susan Quilliam
}

Freelance Writer, Broadcaster and Agony Aunt, Cambridge, UK

Correspondence to

Ms Susan Quilliam, Freelance Writer, Broadcaster and Agony Aunt, Cambridge, UK;

susan@susanquilliam.com

Received 12 January 2011 Accepted 19 January 2011

\section{Background}

In a recent issue of the Journal, I wrote about the importance of enrolling all health professionals in the field of intimate health - in opening the conversation, in diagnosing, referring on, supporting every patient to have a good sex life. ${ }^{1}$ But, of course, there's an additional issue here. We need to not only enrol health professionals in the cause, but also enrol patients themselves. We need to make sure that when patients have an intimate question they are able to mention it to us, discuss it with us, then take our advice on board. So what stops patients bringing us their issues? Conversely, what enables them to do so? And what would make it easier for them to start the dialogue? It's time for another Consumer Correspondent survey.

\section{Where asking questions isn't a problem}

When I began the survey, the first thing that encouraged me was that I had no difficulty in finding respondents to what they soon began calling 'The Cringe Report'. Certainly my contacts, professional and personal, were drawn from a pool of fairly relaxed and uninhibited people, but even so I was gratified to gather 20 eager folk within just a few hours of sending out my invitation e-mail. Unsurprisingly, fewer men than women were prepared to disclose intimate details. More surprisingly, the age range of my respondents was perfectly balanced from those in their early 20 s through to those in their late 60 s.

\section{"Unsurprisingly, fewer men than women were prepared to disclose inti- mate details."}

The second encouraging thing was the number (7) who said that they didn't feel able to contribute to my survey because they personally had never had a problem approaching any health professional about any intimate matter whatsoever.
Some explained that it was simply in their nature to be "so upfront that [I] have no becoming modesty". Others, I'm glad to say, put their lack of inhibition down to the skill and competence of their health professional. Patients credited us with having not only the relevant information to answer queries, but also a consultingroom manner which lowered inhibition and raised trust. "I tend to think that [the staff] have seen and heard it before ...", "They are all excellent ... I never feel nervous or embarrassed".

\section{Who do patients prefer to ask?}

But now we turn to the respondents motivated to answer the survey - sometimes at great length - because they had experienced difficulties. The first question I asked was "What kind of health professional did you consider talking to about an intimate issue?" The range mentioned was wide: general practitioners (GPs) were the first go-to of choice, followed by gynaecologists, midwives, in vitro fertilisation (IVF) specialists, sex therapists, genitourinary medicine clinic staff and a lone homeopath. That most patients went to their GP is to be expected; local generalists are typically the first port of call for health issues and the message here is clearly that GP practices have to be wellresourced if they are to deliver.

However, some respondents were reluctant to approach their GP. Sheer familiarity must play a part here. Particularly in small communities, and given that the GP offers a cradle-to-grave service, does one really want to confide the intimate details of one's sex life to someone who may well have known you since childhood and may also be sitting alongside you at a parentteacher meeting?

Another significant thing about those survey respondents who did not choose to go to their GP is that the professional they did choose to go to was not only qualified 
to deal with sexual issues but was, so to speak, clearly labelled as such. Who would one approach to talk about an intimate matter if not a gynaecologist or a sex therapist? Who is more aware of the fact that one has an active sex life than a midwife or IVF specialist? (So is there a possibility here that practice staff could similarly identify themselves as sympathetic to, or specialising in, intimate queries?)

\section{What questions create 'The Cringe Factor'?}

We come now to the problems themselves, those cringe-worthy issues. Top of the list was "down there". Several respondents didn't like to ask about vaginal irritation, dryness or pain. One didn't feel able to challenge damage done due to incorrect stitching after childbirth. One didn't feel comfortable asking how he should examine his testicles. One gulped at needing treatment for a bad sore located between anus and vagina. While these body parts obviously deserve the same consideration as any other, patients are wary about asking for that consideration.

Next in line were issues around reproduction. Enquiring about the right tests before conception, wondering when it is safe to resume sex during pregnancy, checking options for fertility treatment.

Issues around sexually transmitted infections (STIs) were listed more rarely. Was this because respondents have no problem in mentioning STIs in the consulting room? Sadly no; STIs are still a matter of shameful reticence. Respondents turned to the Web for such information, despite its unreliability, and only approached a practitioner with personalised questions that couldn't be answered by 'surfing'.

A final, and very particular, group of issues can be gathered under the heading 'sexual preference', queries such as "Do I still need to have a smear now that I'm no longer having sex with men?" These issues seemed to be the ones that survey respondents felt most strongly about, presumably because alongside the intrinsic problem they carry the risk of confrontation with society's negative reactions to varying sexual orientation.

\section{What creates 'The Cringe Factor'?}

My next survey question was this: "What blocks did my respondents hit when asking their intimate questions?" Here there were three very distinct groups of answer: those to do with society's attitude to sex; those to do with negative feelings about self; and those to do with reactions on the part of health professionals.

Society's inhibition about sex affected almost all my respondents. They felt awkward about mentioning a problem, embarrassed to ask a question, worried that talk of intimate issues was not acceptable. Respondents seemed to be fully aware that the formal 'contract' with their doctor or nurse meant they could ask, but there was an inbuilt reticence about doing so, an almost visceral 'cringe'.
Negative feelings about self were the next 'block'. Some respondents felt ashamed that they had the symptom or condition they were enquiring about: "I felt a lesser person". Some simply felt that they should already know the information they were requesting, or should be resourced enough to discover it: "I ought to be able to find my own advice" or "I ought to know these things". Several thought that their problems (and, by implication, they themselves) were not important; a good sex life was a luxury, and in asking for help they were somehow being selfish. Yes, these self-accusatory feelings are probably born decades before a particular patient turns up in our consulting room, and there is no way we can - or should even try to - heal all their negativity within a consultation. But it may be useful to register that awkwardness around these issues may come directly from self-blame.

Fascinatingly, all the above emotions - inhibition, embarrassment, accusation - were stronger if a partner was present. Somehow - despite the fact that this partner was presumably also a lover - their very presence in the consulting room raised the stress level. "Weird, I know", as one respondent put it, but perhaps something to be borne in mind. It is typically a good thing to include a patient's nearest and dearest in their health care regime, but it might not be quite so positive when the patient needs the opportunity to ask a more personal question.

\section{How do professionals create 'The Cringe Factor'?}

The third block - and clearly the one most pertinent to this article - was the attitude and behaviour of health professionals.

Respondents mentioned scheduling problems: "I end up feeling it isn't important enough to take up [the practitioner's] valuable time"; "When I call my doctor's office and ask for an appointment, they say 'Is it urgent', and I think the questions I have are never urgent". Respondents mentioned the inability to see a doctor of the same gender: "I can't ask when I have to see a male GP". They mentioned wanting a chaperone "and I didn't like to request one as it would sound as if I were casting aspersions on [the consultant's] professionalism".

They may feel that the professional wouldn't have the correct knowledge - or wouldn't be able to get it. "I genuinely felt that the GP didn't know the right answer." "[I lost] all confidence I might have that practitioners would be knowledgeable."

Sadly, their discomfort may be also due to the health professional's own attitudes to sex. My respondents reported raised eyebrows, pursed lips, fudging of issues, an unwillingness to discuss and an inability to sympathise. "I asked about my options for having children, my doctor said she'd look into this and came back with scant information, which felt like a brush off." "My GP told me my period pains would clear up when I found the right man." 


\section{Facilitating questions: the practicalities}

But let's not get bogged down by complaints. The final part of my questionnaire - and the one which brought forth the most enthusiastic and creative responses from my respondents - asked: "What could [your] health professional do to make it more comfortable for you to discuss intimate problems?" This, surely, is where we can read, learn and inwardly digest (Box 1).

Full accessibility was a consistent request. Many of my respondents had experience of health care worldwide, and more than one contrasted the British public system with "private health care in other countries where regular visits to the gynaecologist [means I] would have asked more questions ... more detailed questions ... for more advice".

Same-gender or same-sexual-preference professionals were another typical ask, particularly from women: this is seen not only to reduce embarrassment but also create an atmosphere of empathy. "They would ... take you more seriously, understand that something is a real problem." Equally, labelled expertise would be welcomed knowing that a practitioner is a specialist in the sexual field, or if a generalist has gained experience or has a particular interest, reduces wariness.

Accurate, trustable up-to-date information - of the sort that patients can't get on the Web - was the fourth demand. Patients do refer to the Internet, but they know enough not to trust it; being able to get facts direct from an expert, ask that expert questions and also discuss personal issues is worth more than any amount of 'surfing'. (And patients don't necessarily expect instant answers. "It's fine to say you'll find out and get back to me.”)

\section{Facilitating questions: the response}

The deeper thread that ran throughout my respondents' answers, however, was that patients also want from professionals a positive emotional response.

Patients want 'permission' to raise issues, this permission given either by general encouragement, "She asked if I had any other questions", or better still a specific and personalised invitation, "I would have been embarrassed to mention the pain, but the doctor asked about it". "The GP enquired about my sex drive as part of my regular health check." "It's always easier to respond to a subject raised by someone else."

\section{"Patients also want from professionals a positive emotional response."}

Patients want a calm atmosphere. They asked for "relaxation", "reassurance", "positive body language", "eye contact", "gentle attention", "language I'm at ease with", "acceptance of my sexual behaviour rather than blame", "awareness that I may not be heterosexual, and that that means different things for my sex life than for many people's".
Box 1 Specific ways to encourage patients to raise intimate issues

1 Make it clear that such issues are acceptable and important: provide in-waiting room leaflets and posters about sexual and reproductive problems.

2 Set out your stall: in-surgery and on your website, specifically offer consultations about sensitive issues.

3 Address the practical blocks: offer the possibility of same-gender or same-sexualpreference consultations, with same-gender chaperones, longer sessions for intimate issues.

4 Support willing staff: send those who want to consult about sexual conditions on courses designed to build comfort and confidence.

5 Let unwilling staff off the hook: let reticent practitioners know that it is fine to refer on to others.

6 Have to hand a list of out-of-surgery sexual specialists (medical and therapeutic) to whom all staff can refer patients for more in-depth advice and help.

\section{Reaching a happy balance}

I freely admit that the results of 'The Cringe Report' are, once known, not rocket science - though it was interesting to me to hear patients' requirements in their own words, and to see clear patterns consistent across all my respondents.

What I did newly realise, however, was the mirrorlike nature of the two sides involved. Because surely what stops patients themselves asking questions are precisely the elements they report that they need from health professionals. They are held back by their own inhibition, awkwardness and embarrassment; they need us to be uninhibited, at ease and professionally unembarrassed. They are blocked by self-accusation; they need us to react in a way that neither shames nor blames. That means that we ourselves need to reach a point of happy balance around sexual issues - and that may not be an easy journey. It may mean challenging our own attitudes to sex, our own personal as well as professional hang-ups, our inhibitions, our own cringe triggers.

\section{"If we can change our approach, then we can change our patients' approach.”}

But I do believe that if we were able to reach a point of balance, then we would see huge benefits. We would see patients more relaxed in themselves and more able to trust us with their deepest concerns - plus crucially, more willing to take our advice on sexual health matters, more willing to accept treatment and work for prevention. In other words, if we can change our approach, then we can change our patients' approach. Cringe could turn to Compliance - now there's a nice thought.

\section{Competing interests None.}

Provenance and peer review Commissioned; internally peer reviewed.

\section{Reference}

1 Quilliam S. Let's mobilise the secret army. J Fam Plann Reprod Health Care 2010;36:249-250. 